\title{
The half maximal effective dose of intravenous oxycodone for blunting the hemodynamic responses to laryngoscopy and endotracheal intubation
}

\author{
Ki Tae Jung, M.D. ${ }^{1}$, Sang Hun Kim, M.D., Ph.D. ${ }^{1}$, Keum Young So, M.D., Ph.D. ${ }^{1}$ \\ Departments of Anesthesiology and Pain Medicine, Chosun University, School of Medicine ${ }^{1}$, Gwangju, Republic of Korea
}

\begin{abstract}
Background and Goal of Study
* Laryngoscopy and endotracheal intubation lead essentially to undesirable hemodynamic changes, which most anesthesiologists have attenuated by pharmaceutical intervention such as opioid and non-opioid analgesics.

* Intravenous oxycodone also can be used for this purpose, but it has different effective dose according to gender as well as age. However, there are no references on the optimal dose to attenuate these hemodynamic changes.

* Therefore, we investigated the half maximal effective dose $\left(\mathrm{ED}_{50}\right)$ of intravenous oxycodone to blunt the hemodynamic responses to laryngoscopy and endotracheal intubation by the Dixon's up-and-down method in male patients.
\end{abstract}

\section{Materials and methods}

* After institutional review board approval, thirty three male patients, aged between 20 and 65 years, were finally enrolled.

* First patients were slowly injected with intravenous oxycodone 0.1 $\mathrm{mg} / \mathrm{kg} 20$ minutes before anesthesia.

* The induction of anesthesia and neuromuscular block was started with propofol and rocuronium.

* And then, 2 minutes later, endotracheal intubation was performed.

* The dose of intravenous oxycodone for each subsequent patient was determined by the response of the previous patient by the Dixon's up-anddown method (DUDM) with an interval of $0.01 \mathrm{mg} / \mathrm{kg}$ according to the degree of hemodynamics changes with $20 \%$ limitation 1 min after intubation.

* The $\mathrm{ED}_{50}$ of intravenous oxycodone was determined by using Dixon up-and-down method which calculating the mean of midpoint dose of all independent pairs of patients who manifested crossover from "response" to "no response" after eight crossover points. Probit regression model was used to calculate dose response curve and confidence intervals and estimated $\mathrm{ED}_{50}$ and $\mathrm{ED}_{95}$ were calculated.

\section{Conclusions}

* The intravenous oxycodone showed the narrow preventive dosage for blunting hemodynamic response to laryngoscopy and endotracheal intubation, and the additional study will be needed to confirm the actual blunting effect of hemodynamic responses to laryngoscopy and endotracheal intubation using the $\mathrm{ED}_{50}$ and $\mathrm{ED}_{95}$ of intravenous oxycodone.

\section{Results and discussion}

Fig. 1. Consecutive dose of intravenous oxycodone for determining the $\mathbf{E C}_{50}$.

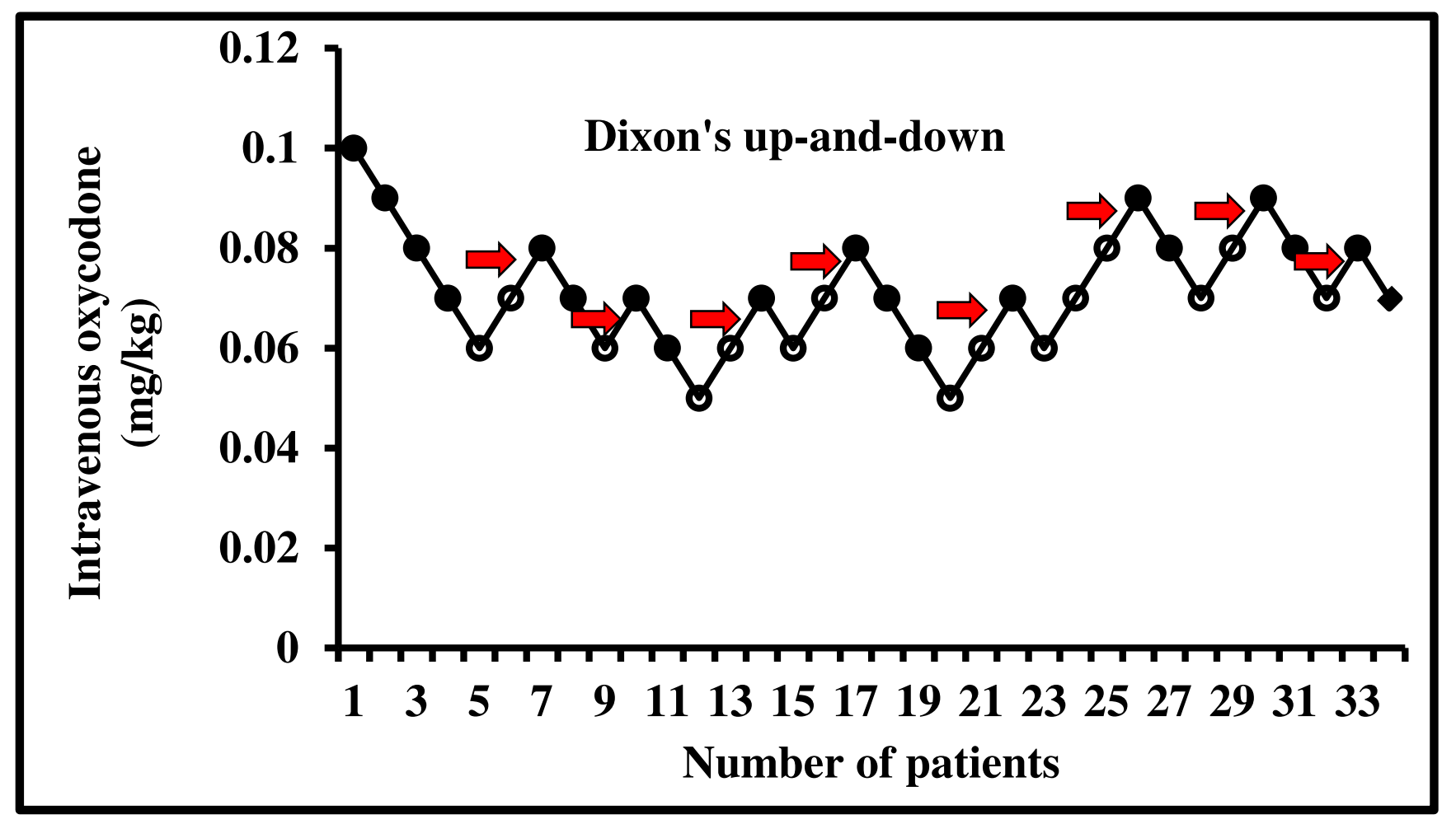

* The $\mathrm{ED}_{50}$ of intravenous oxycodone was $0.074 \pm 0.008 \mathrm{mg} / \mathrm{kg}$ in male

Fig. 2. Dose response curve plotted from Probit analysis

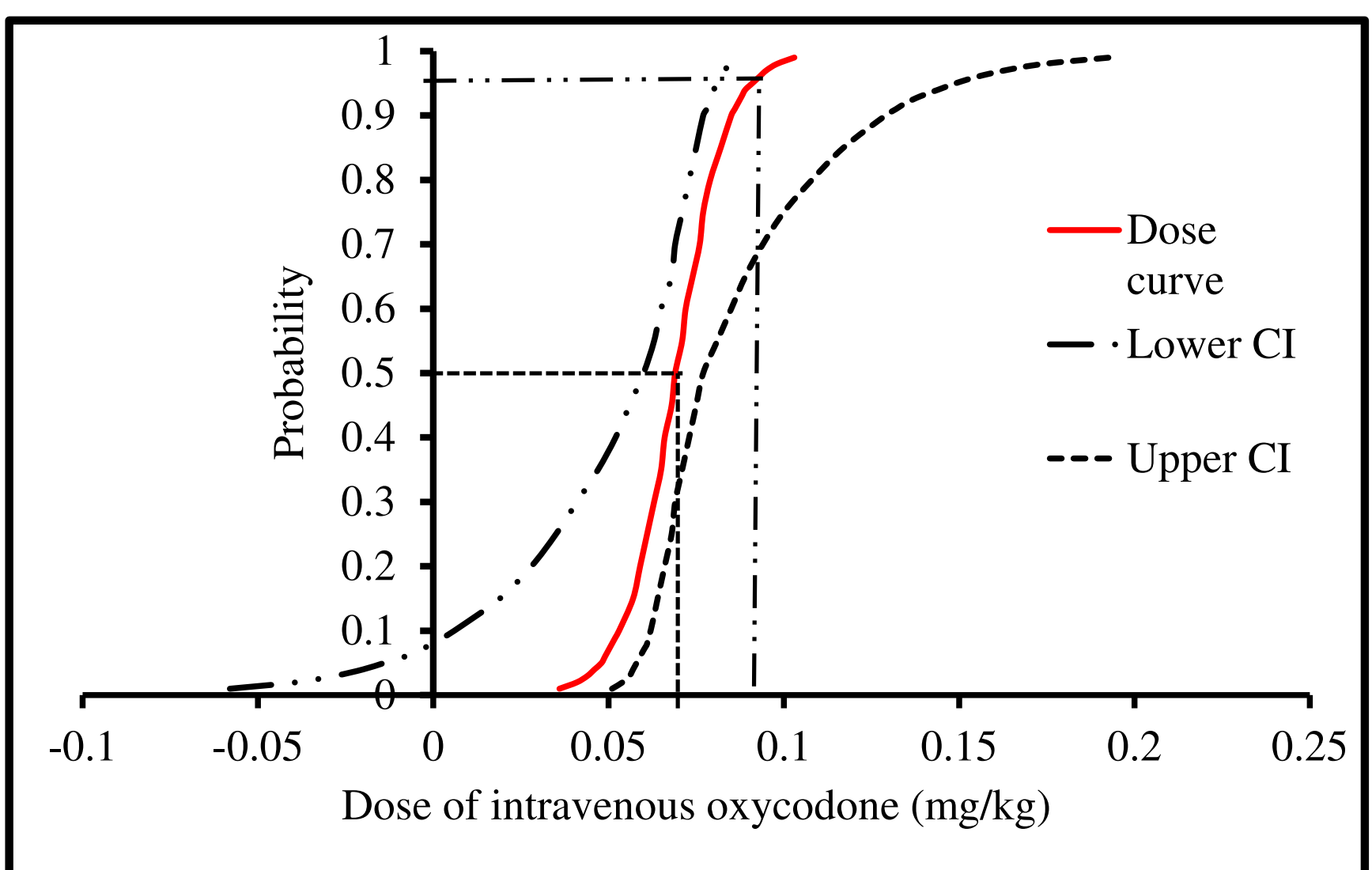

* From Probit regression model, the $\mathrm{ED}_{50}$ and $\mathrm{ED}_{95}$ of intravenous oxycodone were 0.069 [95\% confidence interval (CI), 0.06-0.077] and 0.091 (CI, 0.081-0.149) $\mathrm{mg} / \mathrm{kg}$ in male patients, respectively. patients by DUDM. 